Robert J. Fragen MD, Donald I. Funk MD, Michael J. Avram PH D, Catherine Costello RN, Kimberly DeBruine RN

\title{
Midazolam versus hydroxyzine as intramuscular premedicant
}

The effects of the benzodiazepines range from

A randomized, double-blind, placebo-controlled, study was carried out in which the effects of midazolam $\left(0.08 \mathrm{mg} \cdot \mathrm{kg}^{-1}\right)$ and hydroxyzine $\left(1.5 \mathrm{mg} \cdot \mathrm{kg}^{-1}\right)$, with or without atropine $(0.4 \mathrm{mg})$ or hyoscine $(0.4 \mathrm{mg})$ were compared as intramuscular premedicants. Midazolam produced quicker onset of action, greater anxiolysis for the first hour, greater amnesia, less local irritation and a higher overall rating by the patients. Drowsiness, while also greater after midazolam, was neither marked nor prolonged. Both drugs were given similar overall ratings by the anaesthetists who administered the anaesthetics. Neither drug produced systemic toxicity. Of the two drugs known to produce amitesia, midazolam had a more profound effect and had an earlier onset than hyoscine. Midazolam $\left(0.08 \mathrm{mg} \cdot \mathrm{kg}^{-1}\right)$ shows good potential as an intramuscular premedicant, especially when anassthetic induction occurs 30 to 60 minutes later. Hyoscine, but not atropine, enhances the effects of the sedative drugs.

Key words

PREMEDICATION; midazolam, hydroxyzine.

From the Department of Anesthesia, Northwestem University Medical School and Northwestern Memorial Hospital, Chicago, Illinois.

Address correspondence to: Dr. R.J. Fragen, Department of Anesthesia, Northwestern University Medical School, 303 E. Chicago Avenue, Chicago, Illinois 60611 .

This project was supported in part by a grant from Hoffman-LaRoche, Inc.

This paper was presented in part at the annual meeting of the American Society of Anesthesiologists, 1981. behavioural changes to unconsciousness, depending upon the dose. Midazolam is a water-soluble benzodiazepine which has been studied as an intravenous induction agent for general anaesthesia, ${ }^{1-4}$ and is currently under investigation as a premedicant, by the oral and intramuscular route. Its rapid absorption from intramuscular sites ${ }^{5}$ could justify its use as an intramuscular premedicant. In an earlier dose-finding study of intramuscular midazolam $\mathrm{HCl}$ (unpublished data), it was found that $0.075 \mathrm{mg} \cdot \mathrm{kg}^{-1}$ produced sedation within $30 \mathrm{~min}$ utes after injection and a short period of antegrade amnesia, without local or systemic toxicity. Hydroxyzine was chosen as the drug for comparison because it is an injectable nonbenzodiazepine tranquillizer used for premedication. Hydroxyzine produces sedation with a minimum of systemic side effects, although it can be locally irritating. The recommended dose of hydroxyzine is $0.5-1.5 \mathrm{mg}$ ' $\mathrm{kg}^{-1}$. The present study was designed as a doubleblind, single-dose placebo-controlled, betweenpatient study to evaluate the relative effectiveness of midazolam and hydroxyzine as intramuscular premedicants, and to detennine whether the addition of atropine or hyoscine altered the effects of the tranquillizers when given alone.

\section{Methods}

One hundred and eighty adults, ASA physical status I or II, age 18 to 60 years, and weighing between 50 and $100 \mathrm{~kg}$, consented to participate in this institutionally approved study. Approval had been granted by the institutional review board of Northwestern University. The patients underwent operations of a kind which would not interfere with their ability to answer questions the following day. All patients received either general or regional anaesthesia. They were randomly assigned to one of seven 
groups. One group received the vehicle for midazolam (sodium chloride $9.0 \mathrm{mg}$, disodium edetate $0.1 \mathrm{mg}$, benzyl alcohol $0.01 \mathrm{mg}$, hydrochloric acid 10 per cent and/or 10 per cent sodium hydroxide $v / v$ q.s. to $\mathrm{pH} 3.0-3.3$, water for injection q.s. to $1 \mathrm{ml}$ ) and served as the control group. Three groups received midazolam and the remaining groups were given bydroxyzine. The three groups receiving each tranquillizer were given either 0.9 per cent saline, atropine or hyoscine with the tranquillizer. The doses of drugs administered were midazolam $\mathrm{HCl}$ $\left(5 \mathrm{mg} \cdot \mathrm{ml}^{-1}\right), 0.08 \mathrm{mg} \cdot \mathrm{kg}^{-1}$, hydroxyzine $(50 \mathrm{mg}$. $\left.\mathrm{ml}^{-1}\right), 1.5 \mathrm{mg} \cdot \mathrm{kg}^{-1}$, vehicle for midazolam $0.2 \mathrm{ml}$. $10 \mathrm{~kg}^{-1}$, saline $1.0 \mathrm{ml}$, and atropine or hyoscine $0.4 \mathrm{mg}(1.0 \mathrm{ml})$. All injections were given deep into the vastus lateralis muscle of the thigh approximately 60 to 90 minutes before induction of general anaesthesia or administration of regional anaesthesia. The actual substance contained in the syringe was unknown to the patients, nurse observers and anaesthetists who rated the medication after they had administered the anaesthetic.

Blood pressure, heart rate, and respiratory rate were measured before injection and again 30 and 60 minutes after injection.

The degree of drowsiness was rated on a fivepoint scale by a nurse observer immediately before and at 30,60 , and 90 minutes after drug injection. Drowsiness was evaluated as $0=$ awake/alert, $1=$ awake/drowsy, 2 = asleep/easily responds to verbal commands, $3=$ asleep/difficulty responding to verbal commands, and $4=$ asleep/no response to verbal commands.

Each patient marked a line, an anxiety visual analogue test, immediately before and 30,60 , and 90 minutes after injection. One end of the line was designated the worst anxiety the patient had experienced, designated as 100 per cent anxiety, and the other end as zero anxiety. A patient had to indicate an anxiety level higher than 45 per cent before drug injection to enter the study. Changes in each patient's self-evaluated anxiety level at the stipulated times were later compared.

To test for retrograde amnesia, a conumon object, a ballpoint pen, was shown before injection. Three memory cards, pictures of a dollar bill, a bird or a shoe were shown in random sequence 30,60 , and 90 minutes after injection. The next day patients were asked to recall the pictures; a composite of six pictures, including the three previously shown, was presented and they were asked which pictures, if any, they recognized from the previous day. Druginduced antegrade amnesia was considered to exist only when there was a failure to both recall and recognize a memory picture.

After the anaesthetic, the anaesthetist who ad ministered it was asked to evaluate the overall effect of the premedication as excellent $=4$, good $=3$, fair $=2$, or poor $=1$. This rating was based on the calming plus other observed effects. Patients were asked the next day to give a similar evaluation and were also asked if the medication had caused sleepiness or drowsiness. The injection site was examined for signs of local irritation 24 and 48 hours following drug injection. If erythema, tenderness or induration were present, they were recorded as were any other side effects.

Demographic data were analyzed statistically by a one-way analysis of variance. Comparison of treatments was made with the Wilcoxon rank test by comparing two treatments at a time for anaesthetists' and patients' overall ratings, for the anxiety visual analogue test, and for the level of drowsiness. Analysis of covariance (covariate was baseline score) was used to analyze vital sign changes. The incidence of lack of recall and recognition of memory pictures, incidence of patients' subjective feeling of drowsiness, and incidence of side effects were analyzed with Fisher's exact test. Results were considered to be significant if $\mathrm{p}<0.05$ (one-sided significance level for placebo comparisons, twosided, otherwise).

\section{Results}

The demographic data for each group are shown in Table $I$. The ages, weights, heights, and sex distribution of the groups were similar. The number of patients in each group whose operation might result in a diagnosis of malignancy was similar.

There were no clinically significant changes in blood pressure, heart rate, or respiratory rate, although a statistically significant rise in heart rate occurred 60 minutes after midazolam + atropine (5.1 beats $\left.\mathrm{min}^{-1}\right)$, a decrease in heart rate (78.4 to 69.3 beats min $^{-1}$ ) 60 minutes after hydroxyzine + hyoscine, and a $0.53 \mathrm{kPa}$ decrease in mean arterial pressure 30 minutes after midazolam + hyoscine.

Figure 1 displays the changes in drowsiness for each group at each time interval. The mean and SEM for each group, and the groups showing 
TABLE I Demographic data

\begin{tabular}{llllll}
\hline Growp & $N$ & Males & Age $(y r s)$ & Weight $(\mathrm{kg})$ & Height $(\mathrm{cm})$ \\
\hline Midazolam & 27 & 5 & 32.9 & 69.7 & 169.3 \\
Midazolam + atropine & 24 & 8 & 33.7 & 69.0 & 168.3 \\
Midazolan + hyoscine & 25 & 7 & 34.0 & 65.4 & 167.2 \\
Hydroxyzine & 28 & 4 & 32.1 & 65.9 & 165.2 \\
Hydroxyzine + atropine & 24 & 7 & 35.8 & 68.4 & 166.9 \\
Hydroxyzine + hyoscine & 27 & 7 & 33.0 & 68.4 & 167.6 \\
Placebo & 25 & 6 & 33.6 & 67.9 & 167.2 \\
\hline
\end{tabular}

Values for age, weight, and height are the mean for each group.

Differences among the groups are not statistically significant.

TABLE II Per cent dectease in anxiety

\begin{tabular}{llll}
\hline & \multicolumn{2}{l}{ Time ofter drug injection (min) } \\
\cline { 2 - 4 } Drug(s) & 30 & 60 & 90 \\
\hline Midazolam & $39.7(5.4)^{*}$ & $45.7(6.7)$ & $48.3(7.4)$ \\
Midazolam + atropine & $40.1(6.3)^{*}$ & $47.0(7.5)$ & $66.4(7.3)$ \\
Midazolam + hyoscine & $48.4(5.6)^{*}$ & $54.6(7.7)$ & $61.0(7.5)$ \\
Hydroxyzine & $11.6(4.4)$ & $29.3(7.4)$ & $42.4(10.8)$ \\
Hydroxyzine + atropine & $22.2(5.0)$ & $31.3(8.1)$ & $33.2(11.3)$ \\
Hydroxyzine + hyoscine & $23.6(4.7)$ & $52.3(5.8)$ & $68.9(5.8)$ \\
Placebo & $13.4(5.6)$ & $36.9(7.6)$ & $52.5(10.6)$ \\
\hline
\end{tabular}

Mean ( $(S E M)$ per cent decrease in anxiety from control for each group at each time interval. Other comparisons may be found in the text.

"p $<0.02$ versus all groups receiving hydroxyzine or placebo.

significant differences from placebo can be seen. Drowsiness after all midazolam injections was greater than after placebo, hydroxyzine, or hydroxyzine + atropine at 30 minutes after injection. Drowsiness was produced by all the active drug groups to a greater degree than by placebo at 60 and 90 minutes after injection. Midazolam plus atropine caused greater drowsiness at 60 minutes after injection than hydroxyzine plus atropine. The addition of hyoscine to midazolam produced greater drowsiness at 60 minutes than midazolam alone, and when added to hydroxyzine caused greater drowsiness at all time intervals than hydroxyzine alone or with atropine $(p<0.05)$.

No group differences in initial anxiety level were seen on the anxiety visual analogue test. The per cent change in anxiety after premedication is shown in Table II. At 30 minutes a greater decrease in anxiety occurred in each of the groups which had received midazolam compared to each of those which had received hydroxyzine or placebo $(\mathbf{p}<$ 0.02 ), (Table II), but not later. Hydroxyzine + hyoscine produced a greater decrease in anxiety than hydroxyzine alone at 60 minutes and at 90 minutes after injection and than hydroxyzine + atropine at 90 minutes after injection ( $p<0.05$ ). Atropine or no belladonna alkaloid were not different at any time interval.

There were five of 72 patients who had received midazolam and did not recall the ballpoint pen. They did, however, recall other immediate preinjection events and were not considered to have retrograde amnesia. All other patients recalled the pen.

The incidence of antegrade amnesia is shown in Table III. Significant antegrade amnesia was present 30 minutes after injection in each group who had been given midazolam compared to every other group. At 60 minutes this was also true for the groups with midazolam and a belladonna alkaloid. Midazolam alone caused more amnesia than placebo at 60 minutes. At 90 minutes, the group that had midazolam and hyoscine showed greater amnesia than the hydroxyzine, hydroxyzine + atro- 


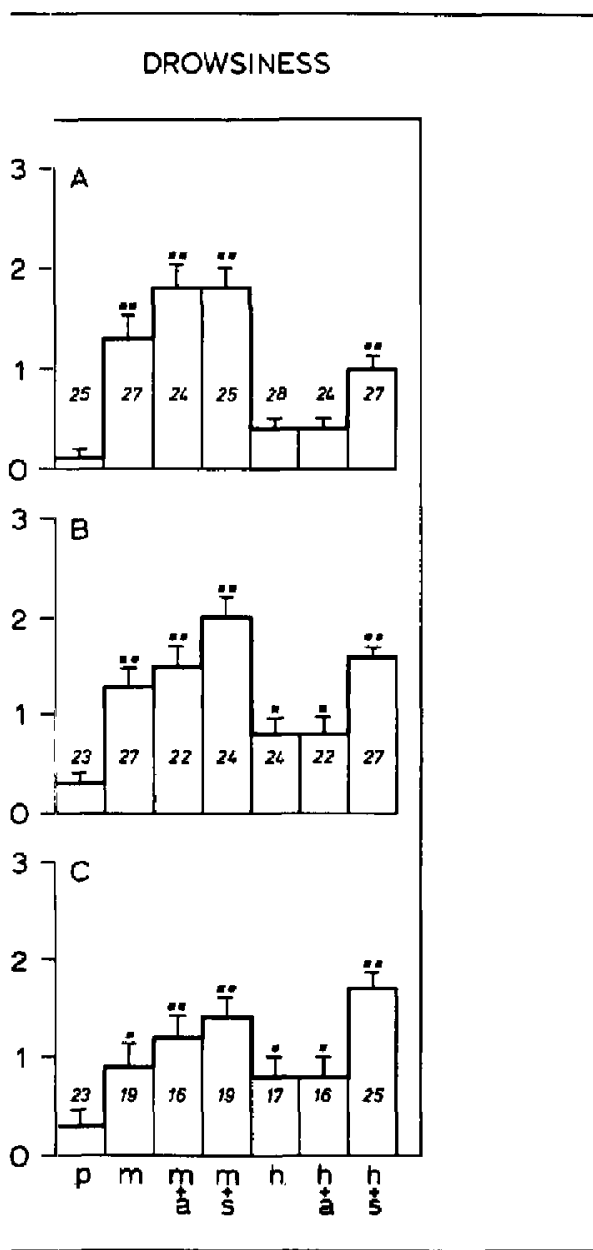

FIGURE I Drowsiness ratings $30 \mathrm{mir}$ (histogram A), $60 \mathrm{~min}$ (histogram B), and 90 min (histogram C) after injection. $P$ = placebo, $\mathrm{M}=$ midazolam, $\mathrm{H}=$ hydroxyzine, $\mathrm{A}=$ atropine and $\mathbf{S}=$ hyoscine. The $\mathbf{N}$ for each group is shown inside or above each column. On the drowsiness scale, baseline is alert awake, $1=$ awake/drowsy, 2 = asleep/easily responds to verbal command, $3=$ asleep/difficulty responding to verbal command. Shown are the mean \pm SEM. $-p<0.05$ $\downarrow=p<0.01$ compared to placebo.

pine or placebo groups. When all patients with midazolam are considered, 50 per cent manifested amnesia for memory pictures 30 minutes after injection and 36.1 per cent 60 minutes after injection.
OVERALL RATING OF MEDICATIONS
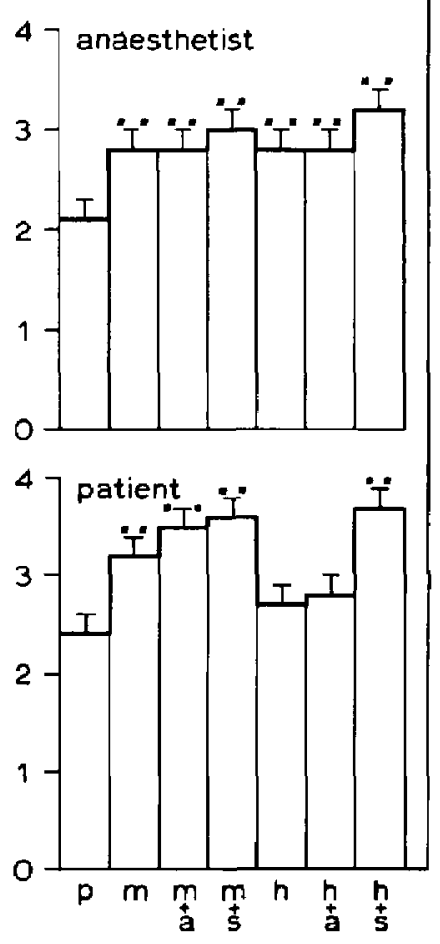

FIGURE 2 On the rating scale $4=$ excellent, $3=\operatorname{good}, 2=$ satisfactory, and $\mathbf{I}=$ poor. $\mathbf{P}=$ placebo, $\mathbf{M}=$ midazolam, $\mathrm{H}=$ hydroxyzine, $\mathrm{A}=$ atropine, and $\mathrm{S}=$ hyoscine. Shown are the mean $\pm S E M$. $\bullet=p<0.01$ compared to placebo. For other comparisons see the text.

For overall effectiveness as a premedicant, the anaesthetists could differentiate midazolam and hydroxyzine from placebo, but not from each other (Figure 2). The patients, however, rated all midazolam injections and hydroxyzine + hyoscine injections higher than placebo. They rated the combinations with hyoscine better than the drugs alone and midazolam alone better than hydroxyzine alone $(p<0.05)$.

Most patients said that the injection made them drowsy when the active drugs were used. The difference was significant $(p<0.01)$ when drugs were compared to placebo, but they did not differ 
TABLE III Failure to both recall and recognize memory pictures

\begin{tabular}{lccc}
\hline & \multicolumn{3}{l}{ Time after injection (min) } \\
\cline { 2 - 4 } Drug(s) & 30 & 60 & 90 \\
\hline Midazolam & $10 / 26^{*}$ & $6 / 26 \ddagger$ & $3 / 19$ \\
Midazolam + atropine & $14 / 22^{*}$ & $10 / 22^{*}$ & $3 / 15$ \\
Midazolam - hyoscine & $12 / 24^{*}$ & $10 / 24^{*}$ & $10 / 20 \dagger$ \\
Hydroxyzine & $0 / 26$ & $2 / 26$ & $1 / 19$ \\
Hydroxyzine + atropine & $1 / 23$ & $1 / 23$ & $0 / 16$ \\
Hydroxyzine + hyoscine & $1 / 27$ & $2 / 27$ & $4 / 23$ \\
Placebo & $0 / 22$ & $0 / 22$ & $0 / 13$ \\
\hline
\end{tabular}

Number of patients who both failed to recall and recognize memory pictures'number of patients in the group at each time interval.

${ }^{*} p<0.05$ versus all hydroxyzine groups and placebo.

$\dagger_{p}<0.05$ versus hydroxyzine, hydroxyzine + atropine and placebo.

$\ddagger p<0.05$ versus placebo

from one another. A feeling of drowsiness was described more often when hyoscine had been added to hydroxyzine than when only hydroxyzine had been injected $(p<0.01)$.

Erythema was seen at the injection site in three of 76 after midazolam. More severe reactions, tenderness and induration, occurred in 51 of 79 after hydroxyzine ( $p<0.01$ ). The only other side effect that could be attributed to the premedication was postoperative dysphoria exhibited by four patients after hyoscinc.

\section{Discussion}

Non-phenothiazine tranquillizers are frequently prescribed for premedication, either alone or in combination with analgesics, because they have fewer detrimental effects on blood pressure and respiration than do narcotics and barbiturates. We compared two tranquillizers, midazolam and hydroxyzine, with and without the addition of the commonly used belladonna alkaloids, atropine and hyoscine. The equivolemic doses of atropine and hyoscine used in this study were those commonly prescribed for adults in our hospital. Although these are not pharmacologically equivalent doses, we felt that it was important to determine whether the combination of hyoscine, $0.4 \mathrm{mg}$ and midazolam, $0.08 \mathrm{mg} \cdot \mathrm{kg}^{-1}$, would produce undesirable amnesic or hypnotic effects. A high dose of hydroxyzine was selected to avoid prejudicing the study. The ability of hydroxyzine to relieve anxiety did not differ from that of placebo, except when combined with hyoscine. We also confirmed the local toxicity of hydroxyzine; some patients complained of local irritation for one week after injection. This degree of local toxicity might possibly be explained by the high dose of hydroxyzine administered.

Midazolam did not produce local irritation and the early onset of clinical effects parallels the rapid absorption from intramuscular sites. ${ }^{5}$ Drowsiness, anxiolysis and antegrade amnesia were most pronounced at the 30 -minute observation point.

Drowsiness after midazolam alone or with atropine was neither marked nor prolonged and it was decreased in intensity after 30 minutes. When hyoscine was added, drowsiness decreased after 60 minutes.

Anxiolysis was produced by midazolam to a greater degree than placebo or hydroxyzine only at the 30 minutes observation period. We ascribe these results to a greater placebo effect with time and a decline in the effect of midazolam after one hour. Although greater relief of anxiety after placebo than after some drug combinations appeared to be present at 60 minutes and 90 minutes after injection (Table II), these numerical differences were not statistically different.

The correlation between the degree of drowsiness and the relief of anxiety was not consistent when we compared these two effects at the difference time intervals or when we compared the differences in drug effects from placebo. It, therefore, could not always be predicted how relaxed a patient may be by their degree of drowsiness.

Antegrade amnesia was produced in half the patients after midazolam and it usually lasted an hour. This was a longer amnesic effect than seen by Dunde $^{8}$ when midazolam was given intravenously in similar doses. When the amnesic effect of intramuscular midazolam is compared to oral diazepam and oral lorazepam, ${ }^{9}$ it is found to produce a greater amnesic effect than both orally administered drugs for the first hour after administration, although lorazepam $4 \mathrm{mg}$ produces a much greater frequency of amnesia after an hour. The drowsiness produced by the highest oral dose of diazepam and lorazepam was similar to that produced by intramuscular midazolam.

Differences in amnesic effects of midazolam and hyoscine are clearly shown. Midazolam had a quicker onset with a more pronounced effect. The 
total amnesic effect was greatest when midazolam and hyoscine were combined.

Hyoscine also enhanced the drowsiness, anxiolytic effect and patient rating of hydroxyzine but only slightly enhanced the same effects when added to midazolam. The dysphoria produced in four patients after hyoscine, two with each tranquillizer, was easily reversed with physostigmine. Atropine did not alter the effects of either tranquillizer.

Although there were not enough male participants for meaningful comparisons, no apparent differences in drug effects between sexes were noted. No study to date has specifically addressed this question for midazolam.

We conclude that because of the early onset of sedation and amnesia, lack of marked or prolonged drowsiness, absence of systemic or local toxicity, and good ratings by both patients and anaesthetists, midazolam, $0.08 \mathrm{mg}^{\prime} \mathrm{kg}^{-1}$, appears to be a promising intramuscular premedicant when there is a relatively short interval between premedication and induction of anaesthesia. Hyoscine can prolong the amnesic effect and slightly enhance the other effects if the addition of a belladonna alkaloid is desired.

\section{References}

1 Reves JG, Corssen G, Holcomb C. Comparison of two benzodiazepines for anaesthesia induction, midazolan and diazepam. Can Anaesth Soc J 1978; 25: 211-4.

2 Reves JG, Samuelson PN, Lewis $S$. Midazolam maleate induction in patients with ischaemic heart clisease: Hacmodynamic observation. Can Anaesth Soc J 1979; 26: 402-9.

3 Fragen RJ, Gahl F, Caldwell NJ. A water soluble benzodiazepine, RO 21-3981, for induction of anesthesia. Anesthesiology 1978; 49:41-3.

4 Connor JT, Katz RL, Pagano RR, Graham CM. RO 21-3981 for intravenous surgical premedication and induction of anesthesia. Anesth Analg 1978; 57: $1-5$.

5 Crevoisier PC, Eckert M, Heizmann P, Thurneysen $D J$, Ziegler WH. Relation entre l'effet clinique et la pharmacocinétique du midazolam après administration i.v. et i.m. Arzneim-Forsch'Drug Res 1981; 31: 2211-5.

6 Hollander $M$, Wolfe DA. Non-parametric statistical methods. New York: John Wiley and Sons (1973).
7 Cooper BE. Statistics for experimentalists. Oxford: Pergamon Press (1969).

8 Dundee $J W$, Wilson $D B$. Amnesic action of midazolam. Anaesthesia 1980; 35: 459-61.

9 Kothary SP, Brown ACD, Pandit VA, Samra SK, Pandit SK. Time coursc of antirecall effects of diazepam and lorazepam following oral administration. Anesthesiology 1981; 55: 641-4.

Résumé

On a fait une étude randomisée à double inconnue et contrólée par le placebo pour comparer les effets du midazolam $\left(0.08 \mathrm{mg} \cdot \mathrm{kg}^{-1}\right.$ ) et de l' hydroxyzine ( $1.5 \mathrm{mg}$. $\left.\mathrm{kg}^{-1}\right)$ avec ou sans atropine $(0.4 \mathrm{mg})$ et avec ou sans hyoscine $(0.4 \mathrm{mg})$ comme agents de prémédication intramusculaire. Le début de l'action avec le midazolam fut pius rapide et produisit une plus forte réduction d'anxiété pendant la première heure; l' amnésie fut plus élevée mais il y eut moins d'irritation locale et l'evaluation globale par des patients fut plus élevée. L'assoupissement, quoique plus profond après l'administration du midazolam, he fut cependant pas prononcé et ne dura pas longtemps. Cex deux médicaments sont donc évalués comme similaires par les anesthésistes qui administrèrent ces anesthésiques. Aucun des médicaments ne produisit de toxicité systémique. Des deux médicaments connus pour induire l'amnésie, le midazolan a une action plus intense et plus rapide que l'hyoscine. Le midazolam $\left(0.08 \mathrm{mg} \cdot \mathrm{kg}^{-1}\right)$ se manifeste comme une prémédication intramusculaire potentielle, particulièrement lursque l'induction anesthésique se produit entre 30 er 60 minutes après son administration. L'hyoscine, mais non l'atropine, augmente l'action des médicaments sédatifs. 